\title{
IEA/WHO toolkit for WMSDs prevention: criteria and practical tools for a step by step approach
}

\author{
Enrico Occhipinti ${ }^{\mathrm{a},}{ }^{*}$, Daniela Colombini ${ }^{\mathrm{b}}$ \\ ' Research Unit Ergonomics of Posture and Movement, Foundation Policlinico Ca' Granda-Via San Barnaba, 8. \\ 20122 Milano-Italy. \\ ${ }^{\mathrm{b}}$ Research Unit Ergonomics of Posture and Movement, Don Gnocchi Foundation - Milano-Italy
}

\begin{abstract}
When studying WMSDs, several determinants and their interrelationship are considered as relevant. Hence the necessity of an "holistic" approach to prevention, especially when preparing technical rules and strategic plans. There is a strong request, from OSH agencies and operators, for developing "simple" tools for risk assessment and management. In this context WHO asked IEA to develop a "Toolkit for WMSD prevention". The paper presents one of the main contribution to this WHO project, focused on selecting tools at different level for hazard identification, risk estimation and management. Proposals are based on two essential criteria: Acting on a step-by-step approach; Taking into account the presence of multiple influencing factors. The proposals consider: A Basic Step devoted to hazard identification by operative "key-enter" questions, that can be operated also by non-experts. A First Step, (quick assessment), for identifying 3 possible conditions: acceptable; high risk present; more detailed analysis (via tools presented at second step) necessary. This step can be operated by non-experts with only some specific training. A Second Step, where recognized (i.e. from international standards or guidelines) tools for risk estimation are used. This step can be operated only by persons with some specific training.
\end{abstract}

Keywords: WMSDs, Risk assessment, Simple tools

\section{Introduction}

There is a general consensus on the multifactorial nature of Work Related Musculoskeletal Disorders (WMSDs) in the modern society .

WMSDs are mainly caused by working activities involving load manual handling (or manual materials handling), heavy physical job, awkward postures, upper limb repetitive movements or exertions, vibrations. Moreover, the risk for WMSDs can increase versus high working paces, low job satisfaction, high job demand and working stress.

On the other side it is well known that for each of the above general conditions (LMH, heavy physical work, awkward postures, repetitive movements) manifold working risk determinants are to be considered in an integrated way and organizational fac- tors (pace, duration, break, task rotation) play a basic role in determining the overall exposure level.

When studying WMSDs, several determinants of different (mechanical, organizational, psychosocial, individual) nature considered to be significant in general models of risk genesis, assessment and management and for epidemiologic purposes. As a consequence an "holistic" approach to their prevention was confirmed specially at international and national level when planning guidelines and interventions. It is to be clarified that by "holistic" we mean something integral, organic, complex, global, multifactorial that can (and must) be treated with an inter (or meta) disciplinary approach.

It is to be recalled that WHO, while asking International Ergonomic Association (IEA) for a proposal of a toolkit for WMSDs prevention, after a prelimi-

\footnotetext{
*Corresponding author. E-mail: epmenrico@tiscali.it..
} 
nary discussion, agreed with IEA that it should be based on an holistic and non-fragmentary approach.

However, nearly opposed to such a requirement and just considering the widespread diffusion of WMDSs and related manifold causal factors (mechanical, organizational, psychosocial) at many workplaces, operators and national and international agencies involved in prevention have been increasingly asking for simple tools for assessment and management of specific risk to be used also by unskilled workers in developed and developing countries. WHO, while outlining the toolkit development for WMSDs, defines it as "a set of practical risk assessment procedures and related management guidance documents, including advice on simple risk control options" [11]. The toolkit should provide a full model for identification, assessment and check of work-related hazards. It should be simple and practical as well as usable also by unskilled people in Small and Medium Companies (SME) and in developing countries.

Another International body (ISO), after defining a number of technical standards of "physical ergonomics" of working postures, load manual handling, repetitive manual work (ISO 11226 and 11228 series) $[3,4,5,6]$, is now committed through a special application document (ISO TR 12259) to better clarify application procedures and modalities of the methods reported in such standards and even more to operationally indicate the "key-enters" and "quick evaluation" of hazards treated by standards.

Hence the number of reported examples leads to defining the issue that will be tackled in this paper: how to start from an holistic approach to WMSDs prevention and get to use simple tools also by unskilled people. In other words: how to simplify complexity?

\section{Proposals: general issues}

The proposals presented here are aimed at simplifying complexity and are based on two basic criteria:

1. acting with a step-by-step approach (by levels) using first basic tools and then progressively more complex tools only if actually necessary for prevention purposes.

2. taking always into account the overall issues and the presence of manifold risk determinants at every step (even if with different degrees of indepth examination).

It is to be remarked that such proposals were mainly developed in the frame of the WHO/IEA col- laboration project for the "toolkit for MSD prevention" strongly involving EPM research unit as the coordinator of IEA TC on MSD and also as an integral part of CC/OMS at the Clinica del Lavoro Luigi Devoto of Milan. However they also arise from other converging requests such as for example ISO document (ISO TR 12259, at present under final discussion) applying the ISO 11228 series standards.

With reference to the first criterium, it is well known for example that the above mentioned ISO technical standards adopt a general approach to risk assessment and management according to four basic steps:

$\begin{array}{ll}\text { - } & \text { hazard identification; } \\ \text { - } & \text { risk estimation; } \\ \text { - } & \text { detailed risk evaluation; } \\ & \text { risk reduction }\end{array}$

This approach is largely shared in the practice by prevention operators and anyhow is fully corresponding to all the purposes mentioned here, being helpful in detailing the present proposal. As a consequence the proposed toolkit envisages the following levels:

\section{BASIC LEVEL}

Addressed to preliminary identification of the main hazards (or problems) associated with working condition and priority identification via "Key Enters". Ideally this level concerns all the possible hazards (or problems) in the field of ergonomics, industrial hygiene and occupational medicine. This paper however will be more focused on key issues regarding hazards (or problems) for the musculoskeletal system. This level can be operated also by unskilled staff with limited education and training.

\section{FIRST LEVEL}

Focused on risk factors for WMSDs and consisting of a "quick assessment" of identified hazards (via Key Enters). This level can be operated also by unskilled staff with a minimum education and training.

\section{SECOND LEVEL}

As a result of the first level, recognized risk estimation tools are used (mainly from international standards or guidelines). Such tools should be able to adequately consider the main risk determinants. This level can be operated only by staff with some specialist education and training.

Beyond the second level, if the study (finalized to subsequent stages of preventive measure adoption) needs more details, reference can be made to more analytical methods proposed by standards or literature. Detailed methods however have to be used only upon circumstances by skilled and trained staff..

Criteria and examples for every level will be reported. 
Besides, this presentation is not directly aimed at providing a list or a review of tools available in the literature, international standards and guidelines. In this sense, several review documents are already available: proper information on some more complete and recent documents will be generally provided.

Moreover, in a proper Appendix for the use by IEA and WHO (not in this paper), a non exhaustive review of several tools will be reported by "individual forms"; these individual forms were ad hoc prepared on the basis of these review documents and corresponding websites as found in literature and in the web.

Finally let us remind that attention has been focused on tools and procedures considering, at any level, the main WMSDs determinants.

\section{Entry level}

It is aimed at checking the existence of a working hazard/problem (hazard identification) - in this particular case for WMSDs - and whether a further analysis is necessary.

The "problems" associated with WMSDs are to be considered together with other occupational (physical, chemical, etc.) hazards for more general prevention purposes.

In WHO (and IEA) perspective this means to ideally avail of a common basic tool for the whole toolbox (gallery of toolkits devoted to different working risk factors) devoted to occupational health.

As for WMSDs risk factors, there are several proposals of key enters to identify crucial conditions (or hazards).

It is worth mentioning here, as an example, the proposal included in the "Ergonomic Rule" of the Washington State- US [2]. It defines the so called "caution jobs" as the works characterised by activities involving, with well-defined time modalities (e.g. for over 2hours/day), specific risk factors detailed in an appropriate table and regarding awkward postures, use of force, movement repetitiveness, repetitive impacts, load lifting, vibrations transmitted to hand-arm system. In the presence of a caution job it is suggested to submit it to a further more detailed assessment to establish the actual presence of a WMSDs risk. Besides, it is specified that defining a condition of caution job does not mean that it is automatically hazardous but needs a further investigation. As regards such proposal, no doubt significant one, it is however worth emphasizing it do not strictly represent the key enters for the need of a further assessment (that may be either positive or negative) of a potential biomechanical overload condition. It rather try to outline (at least minimum) conditions where such a risk exists.

On account of these considerations, it is therefore necessary, specially for unskilled people, to define much simpler, more basic and neutral key entries (as to the outcome of the subsequent assessment) able to represent the application field of an (even simplified) assessment methodology that will definitely resolve from time to time about the existence or not of a significant exposure to a biomechanical overload condition.

With this view, that is defining simple and operating key enters, it is useful to adopt criteria and definitions provided by (ISO and CEN) international technical standards on this subject. It is worth mentioning that within ISO a "Technical Report" (TR ISO 12259 ) is at its final stage for practical application of ISO 11226 and 11228 (parts 1-2-3) standards concerning working postures, load manual handling and upper limb repetitive movements. The TR is aimed at favouring the actual application of such standards and resumes definitions, criteria and methods and implements them operationally specially when defining entries to use of standards and/or quick assessment on general elements.

Table 1 reports the "key enters" representing the basic (entry) level of hazard identification for the consequent application of related ISO standards.

Finally let us recall an interesting overall proposal set forth by the Occupational Health and Safety Council of Ontario (OHSCO) of Canada for a Toolbox for WMSDs prevention [8]. The proposal, involving also relevant management suggestions, includes a special chapter called "getting started" also different options of a tool (a checklist) for hazard identification (and selection of consequent priorities) associated with WMSDs from lifting, pushing and pulling (with limbs or whole body), use of force, awkward postures or prolonged fixed postures of neck, trunk, upper limbs (several segments), lower limbs, type of grasp, repetitiveness and other major factors (vibrations, repetitive impacts, compressions, microclimate). Once the hazard has been identified, except for a possible more detailed risk analysis needing second level methods (see below), intervention procedures are suggested according to priorities and concrete solutions for limiting the main risk determinants . 
Table 1

Key enters to the evaluation of different conditions of biomechanical overload as considered in ISO 11226 and 11228 (parts 1-2-3)

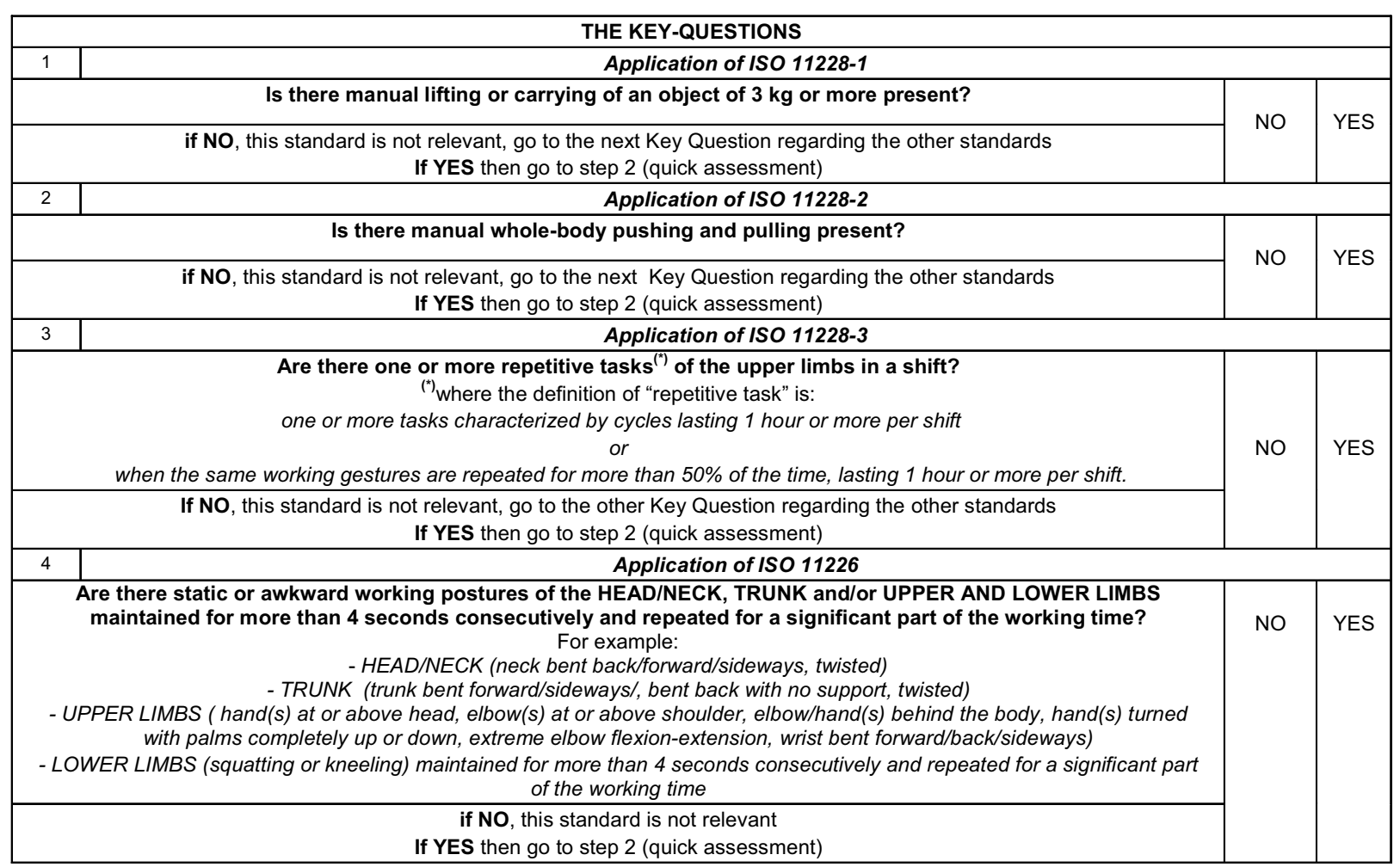

\section{First level (Quick assessment)}

This level consists in quickly checking the presence of potential hazard conditions (for WMSDs) via simple quali/quantitative questions. It is essentially aimed at identifying in a simplified way, three possible outputs: 1) acceptable (green): no actions are needed; 2) critical (very red): it is urgent to redesign the workplace or the work process; 3 ) a more in-depth investigation is needed through a detailed estimation or assessment via second level tools.

Such level, specially if aimed at quickly checking acceptable conditions, is often explicitly present in the mentioned international technical standards.

On the other hand, for quick assessment of surely critical conditions, it is possible to apply definitions and criteria inherent in the methods recommended by standards setting the presence of one or more extremely problematic elements. Such are for example values of weights lifted beyond the maximum recommended value, extreme load lifting areas, ex- tremely high action frequencies with upper limbs, presence of repetitive maximal strength demands.

As to the specific purposes of this level, the ISO Application Document helps us to outline the questions quickly checking predictable acceptability and surely critical conditions.

Consider that for the latter (and only for them), in principle the checklist of the Washington State USA could have been used to identify the so called "hazard zone jobs" [2].

However it was preferred to choose the criteria and solutions emerged when defining the ISO Application Document since they prove to be more coherent with the related reference standards.

Tables 2 and 3, as an example, shortly report the criteria for a quick "acceptability and criticality" assessment of load lifting as at ISO 11228-1 standard [4]. Other examples, for instance regarding repetitive exertions, will be give in another paper in the conference. 
Table 2

Quick assessment for manual lifting activities: check of an acceptable condition (green area)

\begin{tabular}{|c|c|c|c|}
\hline \multicolumn{4}{|c|}{ LIFTING: QUICK ASSESSMENT : ACCEPTABLE CONDITION } \\
\hline \multirow{4}{*}{3 TO 5 Kg } & \multirow{4}{*}{$\begin{array}{l}\text { Asymmetry (e.g. body rotation, trunk twisting) is absent } \\
\text { Load is maintained close to the body } \\
\text { Load vertical displacement is between hips and shoulders } \\
\text { Maximum permissible frequency: less than } 5 \text { lifts per minute }\end{array}$} & NO & YES \\
\hline & & NO & YES \\
\hline & & NO & YES \\
\hline & & NO & YES \\
\hline \multirow{4}{*}{$5,1 \mathrm{TO} 10 \mathrm{Kg}$} & \multirow{4}{*}{$\begin{array}{l}\text { Asymmetry (e.g. body rotation, trunk twisting) is absent } \\
\text { Load is maintained close to the body } \\
\text { Load vertical displacement is between hips and shoulder } \\
\text { Maximum permissible frequency: less than } 1 \text { lift per minute }\end{array}$} & NO & YES \\
\hline & & NO & YES \\
\hline & & NO & YES \\
\hline & & NO & YES \\
\hline MORE THAN $10 \mathrm{Kg}$ & Loads more than $10 \mathrm{~kg}$ are not present & NO & YES \\
\hline
\end{tabular}

Table 3

Quick assessment for manual lifting activities: check of a surely "critical" condition ("very" red area)

\begin{tabular}{|l|l|c|}
\hline \multicolumn{3}{|c|}{ LIFTING AND CARRYING-QUICK ASSESSMENT : CRITICAL CONDITION (CRITICAL CODES). } \\
If only one of the following conditions is present, risk has to be considered as HIGH and it is necessary to proceed with task re- \\
design
\end{tabular}




\section{Second level (simple risk estimation)}

At this level, as a consequence of operational outcomes provided by previous level, exposure (or risk) estimation is to be made considering one or more potential biomechanical overload conditions of the musculoskeletal system. With this view appropriate and recognized risk estimation methods and tools are to be used as from qualified literature or better international standards and guidelines. Such tools should be able to appropriately consider the main risk determinants.

It will be apparent that, in this case, methods and tools proposed by international technical standards on the subject (in particular ISO standards) will be privileged, since they already, when discussing proposals, had implemented specific and targeted reviews of relevant methodologies.

It is however appropriate to account for the altogether of methods largely cited in the literature (regardless of their inclusion or not into technical standards) and used in the different geographic areas of the planet. We do not intend to make here an analytical review of such methods since it would fall outside the scope of this work but reference will be made (and also because of this) to two recent sufficiently exhaustive bibliographic references on this subject.

The first is a work "Systematic review of observational methods assessing biomechanical exposures at work" by a reputed panel experts from Scandinavian countries published in the first issue of 2010 in Scandinavian Journal Work Environment and Health [9]. It makes a survey of several methods, general ones as well as methods specifically concerning spine overload from manual handling and methods concerning upper limb overload. Detailed information is provided for each one them (e.g. factors considered, filling procedures, etc) as well as comments on validity, applicability and possible users.

Details can be found at http://www.ttl.fi/en/ergonomics/workload_exposure methods/pages/default.aspx

A second source of "second level" methods' review comes again from the above mentioned toolbox produced by the Occupational Health and Safety Council of Ontario (OHSCO) of Canada and in particular from chapter "More on In-depth Risk Assessment Methods" [8]. With a maybe more pragmatic approach, the variety of available methods are investigated and discussed to deepen assessment of different biomechanical overload conditions.
Details can be found at http://www.esao.on.ca/downloads/MSD.aspx

Apart from this, we are here definitely oriented towards the proposals and methodologies included in international technical standards (in particular ISO) since they have already been chosen as international level for method validity and applicability. Basically, one may refer to the example of methods revised and proposed by ISO 11228-3 [6] concerning assessment and management of high frequency repetitive manual activities. A special information enclosure attached to this standard, after declaring to assume as a general reference model the one proposed by a consensus document produced by the IEA TC on WMSDs [1], proposes, selects and discusses the detailed risk estimation and assessment method of upper limb biomechanical overload better reflecting that consensus document and standard goals.

As a service for the readers and users of this document, we want again to address to the individual methods forms reported in a separate Appendix (not in this paper); the main methods considered are reported in Table 4. The individual forms were prepared for a general document considering the sources already addressed [8,9], other relevant literature and specific websites concerning the different methods considered.

Considering this short review of second level methods for risk estimation and evaluation, the preference on methods suggested by technical standards on the subject is confirmed as reported in table $\mathbf{5}$, considering the different conditions of potential biomechanical overload of musculoskeletal system.

This choice is strengthened by the options coming forward at the definition stage of the already quoted "Application document" for ISO 11228 series and ISO 11226 standard.

Actually this document confirms:

- usefulness of RNLE method of NIOSH also in view of assessing, if strictly necessary in a simplified way, complex (variable and sequential) lifting activities, according to recent proposals in the literature $[10,11]$ and translated into free applicative software that can be downloaded from dedicated websites (e.g. www.epmresearch.org) .

- usefulness of OCRA checklist method to assess upper limb repetitive manual activities with particular reference to rotation conditions in several repetitive tasks according to the techniques reported in ISO 11228-3 standard and further developed by authors for so called infrequent rotations [7]. In this case as well applicative software are available to be 
freely downloaded from website www.epmresearch.org.

The use of above methods for complex (repetitive or lifting) tasks, though aided by simple and easily accessible software, looks like an advanced second level to be tackled only by people with a sufficient training degree in basic techniques.

It is also worth recalling that beyond the second level, more detailed risk assessment methods are available, both observational ones (e.g. the OCRA index method) and instrumental ones (e.g. electromyographic techniques combined with electrogoniometric recordings and analysis of 3D movement). Such techniques are to be used when the study (addressed to subsequent stages of preventive measure adoption) strictly needs more in-depth details and are for experts' use only; their examination however is outside the scope and logics of the present proposal.

Finally a major problem is the application of the above mentioned estimation methods in special sectors (such as building, agriculture or cleaning) where several tasks with biomechanical overload are carried out in different time periods (the working cycle is accomplished in a time span wider than one day, like for example one month or one year).

For such sectors, in order to simplify the operator's work on the field, it could be useful to:
- set up accessible database via web, where the most common manual tasks (with related variants) found in these sectors are intrinsically evaluated by experts (intrinsically means regardless of time and organization patterns as if carried out along the whole working time).

- prepare models and software for analysing multiple tasks over the long period: preliminary models are already available even if they need further validation

- ask the users to collect simple organizational data in their specific contexts and apply them together with pre-evaluated data in provided models and software.

Preliminary database of pre-evaluated manual repetitive tasks are available at present, being the outcome of collaborations with Italian, Spanish, Chilean and Cuban colleagues in the following sectors: agriculture (mainly wine growing), clearing (mainly in hotels and public buildings), stores (all tasks), building (only few tasks). They have been often reported in IEA triennial conferences.

A wider collaboration network (within the IEA/WHO collaboration framework) to increase database is needed: all collaborations in this regard will be useful for spreading knowledge to operators on the field.

\section{ACGIH TLV for Low back Risk}

Washington State Ergonomic checklist (caution job)

HSE Upper limb risk assessment method (and ART)

NIOSH Lifting Equation (RNLE)

OCRA Index an OCRA Checklist

OWAS

REBA (Rapid Entire Body Assessment)
ACGIH TLV for Monotask handwork

Washington State Ergonomic checklist (hazard job)

Manual Handling Assessment Charts (MAC)

Psychophysical Tables for Pushing, Pulling and Carrying

$\underline{\text { Strain Index (SI) }}$

Upper limb expert tool by Ketola

RULA (Rapid Upper Limb Assessment)

\section{PLIBEL}


Table 5

Main methods for second level, suggested in this proposal for "risk estimation", as derived from different international standard.

\begin{tabular}{|c|c|c|c|}
\hline \multicolumn{4}{|c|}{$\begin{array}{l}\text { METHODS FOR SIMPLE RISK ESTIMATION (SECOND LEVEL) DERIVED BY INTERNATIONAL STANDARDS } \\
\text { AND SUGGESTED AS PREFERRED IN PRESENT PROPOSAL }\end{array}$} \\
\hline $\begin{array}{l}\text { Manual } \\
\text { Lifting }\end{array}$ & $\begin{array}{l}\text { Manual } \\
\text { Pushing and Pulling }\end{array}$ & $\begin{array}{c}\text { Repetitive Movements and } \\
\text { Exertions } \\
\text { (Upper limbs) }\end{array}$ & $\begin{array}{l}\text { Working } \\
\text { Postures }\end{array}$ \\
\hline $\begin{array}{l}\text { Revised Niosh Lifting } \\
\text { Equation (RNLE) }\end{array}$ & $\begin{array}{l}\text { Psychophysical Tables by } \\
\text { Snook and Ciriello }\end{array}$ & OCRA Checklist & $\begin{array}{l}\text { OWAS } \\
\text { REBA }\end{array}$ \\
\hline $\begin{array}{l}\text { From ISO 11228-1 and EN } \\
1005-2\end{array}$ & From ISO 11228-2 & $\begin{array}{l}\text { From ISO 11228-3 and EN } \\
1005-5\end{array}$ & $\begin{array}{c}\text { From ISO } 11226,11228-3 \text { and } \\
\text { EN 1005-4 }\end{array}$ \\
\hline $\begin{array}{l}\text { Use also recent updates regard- } \\
\text { ing variable and sequential lifting } \\
\text { tasks }\end{array}$ & $\begin{array}{l}\text { Use also updates of Psycho- } \\
\text { physical Data. }\end{array}$ & $\begin{array}{l}\text { Use also recent updates regard- } \\
\text { ing rotations between multiple } \\
\text { repetitive tasks. }\end{array}$ & $\begin{array}{l}\text { Use the preferred methods and } \\
\text { recommendations from ISO } 11226 \\
\text { and EN 1005-4 }\end{array}$ \\
\hline
\end{tabular}

\section{Conclusive remarks}

Using a step by step approach and tools validated by experience allow to tackle the challenge of simplifying complexity in WMSDs prevention also in difficult situations such as small companies, craftwork, and in developing countries.

For these targets however some issues are still missing such as:

- promotion of WMSDs prevention plans by national or regional authorities

- improved basic knowledge of operators

- shared spreading of tools and related software.

- development of a database system dedicated to prevention and freely accessible also to non-experts.

Besides, whatever the application level - even if basic - of evaluations and interventions, the impact of organizational issues (frequency, duration, break, rotations, etc) in WMSDs assessment and prevention is to be emphasized.. These issues are quite relevant in determining WMSDs risk and have to be carefully considered at least to the same extent as the more traditional mechanical factors (force, loads, postures, vibrations).

Finally, last but not least, great attention was focused in this document on risk identification and estimation. Actually these are the grounds for any preventive and risk reduction action regarding biomechanical overload on the musculoskeletal system.

Risk reduction being our ultimate goal, collecting, spreading and sharing good practice experience is to be considered as a substantial part of the toolkit initiative for WMSDs prevention.

\section{References}

[1] D. Colombini,. E Occhipinti, N. Delleman, N. Fallentin, A. Kilbom and A. Grieco, A. Exposure assessment of upper limb repetitive movements: a Consensus Document. In Ed. W. Karwowski International Encyclopaedia of Ergonomics and Human Factors, Taylor and Francis, 2001

[2] Department Of Labor And Industries. Ergonomics Rule. In Washington State Department of Labor and Industries WAC 296-62-051, 2000.

[3] ISO. ISO 11226. Ergonomics — Evaluation of static working postures. 2000

[4] ISO. ISO 11228-1. Ergonomics - Manual handling - Lifting and carrying. 2003

[5] ISO. ISO 11228-2. Ergonomics - Manual handling - Pushing and pulling. 2007

[6] ISO. ISO 11228-3. Ergonomics - Manual handling - Handling of low loads at high frequency. 2007

[7] E. Occhipinti, D. Colombini, M. Occhipinti Metodo Ocra : messa a punto di una nuova procedura per l'analisi di compiti multipli con rotazioni infrequenti. La Medicina del Lavoro 2008; 99 (3): 234-241

[8] Occupational Health And Safety Council Of Ontario $(\mathrm{OH}-$ SCO). MSD prevention toolbox.. Musculoskeletal disorders prevention series n.5159A, 2008.

[9] Takala EP et al. Systematic evaluation of observational methods assessing biomechanical exposures at work. Scand J Work Environ Health $2010 ; 36(1): 3-24$,

[10] TR Waters, ML Lu, E. Occhipinti. New procedure for assessing sequential manual lifting jobs using the revised NIOSH lifting equation. Ergonomics 2007; 50(11): 17611770

[11] TR Waters, E. Occhipinti, D.Colombini, E Alvarez , A Hernandez. The Variable Lifting Index: A Tool for Assessing Manual Lifting Tasks with Highly Variable Task Characteristics. Conference Proceedings of $17^{\text {th }}$ IEA Congress of the International Ergonomics Association, August 9 - 14, 2009 Beijing, China.

[12] WHO. Healthy workplaces: a model for action: for employers, workers, policymakers and practitioners. World Health Organization. ISBN 9789241599313. 2010 